\title{
Operation of the Airmodus A11 nano Condensation Nucleus Counter at various inlet pressures and various operation temperatures, and design of a new inlet system
}

\author{
Juha Kangasluoma ${ }^{1}$, Alessandro Franchin ${ }^{1}$, Jonahtan Duplissy ${ }^{1}$, Lauri Ahonen ${ }^{1}$, Frans Korhonen ${ }^{1}$, Michel Attoui ${ }^{1,2}$, \\ Jyri Mikkilä ${ }^{1}$, Katrianne Lehtipalo ${ }^{1,3}$, Joonas Vanhanen ${ }^{4}$, Markku Kulmala ${ }^{1}$, and Tuukka Petäjä ${ }^{1}$ \\ ${ }^{1}$ Department of Physics, P.O. Box 64, 00014, University of Helsinki, Helsinki, Finland \\ ${ }^{2}$ University Paris Est Creteil, University Paris-Diderot, LISA, UMR CNRS 7583, Paris, France \\ ${ }^{3}$ Paul Scherrer Institute, 5232 Villigen PSI, Switzerland \\ ${ }^{4}$ Airmodus Ltd., Pietari Kalminkatu 1 F 1, 00560 Helsinki, Finland
}

Correspondence to: Juha Kangasluoma (juha.kangasluoma@helsinki.fi)

Received: 12 May 2015 - Published in Atmos. Meas. Tech. Discuss.: 10 August 2015

Revised: 23 May 2016 - Accepted: 16 June 2016 - Published: 14 July 2016

\begin{abstract}
Measuring sub-3 nm particles outside of controlled laboratory conditions is a challenging task, as many of the instruments are operated at their limits and are subject to changing ambient conditions. In this study, we advance the current understanding of the operation of the Airmodus A11 nano Condensation Nucleus Counter (nCNC), which consists of an A10 Particle Size Magnifier (PSM) and an A20 Condensation Particle Counter (CPC). The effect of the inlet line pressure on the measured particle concentration was measured, and two separate regions inside the A10, where supersaturation of working fluid can take place, were identified. The possibility of varying the lower cut-off diameter of the nCNC was investigated; by scanning the growth tube temperature, the range of the lower cut-off was extended from $1-2.5$ to $1-6 \mathrm{~nm}$. Here we present a new inlet system, which allows automated measurement of the background concentration of homogeneously nucleated droplets, minimizes the diffusion losses in the sampling line and is equipped with an electrostatic filter to remove ions smaller than approximately $4.5 \mathrm{~nm}$. Finally, our view of the guidelines for the optimal use of the Airmodus nCNC is provided.
\end{abstract}

\section{Introduction}

In suitable atmospheric conditions, gases and vapors form small clusters and nanoparticles. Some of these newly formed particles can subsequently grow into large enough sizes to affect climate by influencing cloud formation and by scattering sunlight (Kerminen et al., 2012). With the development of new particle counters that are applicable to atmospheric measurements of sub-3 $\mathrm{nm}$ particles (Jiang et al., 2011; Sipilä et al., 2009; Vanhanen et al., 2011; Wimmer et al., 2013), measurements of new particle formation have been extended to molecular sizes. Based on laboratory verifications, these new particle counters are able to activate and detect large molecules and molecular clusters. They are deployed in field experiments on the assumption that laboratory calibrations are still valid in atmospheric conditions (Alanen et al., 2015; Almeida et al., 2013; Ehn et al., 2014; Kirkby et al., 2011; Kontkanen et al., 2013, 2016; Kuang et al., 2012a; Kulmala et al., 2013; Rose et al., 2015; Xiao et al., 2015; Yu et al., 2014).

A general method to detect small nanoparticles is to bring the particles into a region of supersaturated vapor, where the vapor will condense onto the particles. Thereby the particles are grown into sizes large enough for an optical detector to count them based on the scattering of light. The supersaturation inside most condensation particle counters (CPCs) is generated by firstly heating up the sample flow and simultaneously saturating it with a working fluid. Secondly, in an 
immediately following region, the flow is cooled down and the working fluid condenses onto the particles (Bricard et al., 1976). Another method to create a high supersaturation of a vapor is to mix a warm flow, which is saturated with the working fluid, with a cooler sample flow. The high supersaturation takes place during and after the flows are mixed. The first mixing-type instrument to create high supersaturation was built by Kogan and Burnasheva (1960). Later, Okuyama et al. (1984) constructed the first mixing-type CPC, a particle size magnifier (PSM), to detect nanoparticles, which was the basis for the mixing-type CPC technology. Various designs of the PSM has been built by, for example, Gamero-Castano and Fernández de la Mora (2000), Mavliev and Wang (2000), Kim et al. (2002), Sgro and Fernández de la Mora (2004), Ito et al. (2011) and Kim et al. (2015). The previous PSMs have been mostly used to investigate various aspects of heterogeneous nucleation and droplet growth in laboratory experiments.

To move from laboratory experiments to field measurements, it is crucial to understand how interactions between the sampled particles, flow characteristics and supersaturated working fluid lead to the resulting particle detection in the sub-3 nm size range (Iida et al., 2009; Okuyama et al., 1984; Stolzenburg and McMurry, 1991). For example, previous research (Iida et al., 2009; Kangasluoma et al., 2013, 2014) has shown that relative humidity of the sample air and chemical composition of the sampled particles affect the smallest detectable size of the particle counters operated with diethylene glycol (DEG). When the CPCs are operated in the field, more uncertainties arise from varying pressure and its effect on the flow rates and activation efficiency, especially at low pressure conditions, such as on mountain tops or on board aircraft (Hermann and Wiedensohler, 2001; Kim et al., 2002; Noone and Hansson, 1990; Saros et al., 1996; Seifert et al., 2004; Takegawa and Sakurai, 2011; Zhang and Liu, 1990, 1991). While these studies investigated the pressure effect in a laminar-flow-type CPC, only Kim et al. (2002) have previously studied the pressure dependency of a mixing-type $\mathrm{CPC}$, and their results are partly specific to their instrument. Sampling of sub- $3 \mathrm{~nm}$ particles also requires special attention, since due to the thermal motion of particles, they can be lost to the sampling line walls. Penetration of the smallest particles through tubes is not very efficient, which is why traditional aerosol sampling inlets are not suited for sub- $3 \mathrm{~nm}$ particle sampling. Therefore sampling of sub- $3 \mathrm{~nm}$ particles requires its own specified sampling lines, which should be characterized for line losses to obtain accurate number concentration measurements.

The instrument of interest in this study is a commercially available mixing-type CPC: Airmodus A11 nano Condensation Nuclei Counter (nCNC), which consists of an A10 Particle Size Magnifier (PSM, Fig. 1) and an A20 butanol CPC. The design of the A10 is based on the PSM design of Sgro and Fernández de la Mora (2004), in which the mixing chamber has only one inlet for the aerosol flow, compared to two (Gamero-Castano and Fernández de la Mora, 2000) or even four (Kim et al., 2002) in the previous designs. An in-depth description of the A10 instrument is given by Vanhanen et al. (2011), although this study describes the model A09. The A10 is essentially the same instrument as the A09, but with improved electronics, software, flow control and therefore improved operation stability. The A10 PSM operates briefly as follows: a saturator flow rate, which is controlled by a mass flow controller, with a variation from 0.1 to $1 \mathrm{~L} \mathrm{~min}^{-1}$, is heated up to around $75-90^{\circ} \mathrm{C}$. The flow is saturated with diethylene glycol (DEG) and it is directed to a mixing chamber together with a temperature conditioned sample flow rate of $2.5 \mathrm{~L} \mathrm{~min}^{-1}$. Once mixed, the two flows are cooled down to $1-5^{\circ} \mathrm{C}$ in the growth tube where the sampled particles grow up to approximately $90 \mathrm{~nm}$. Since the aerosol particles are still too small to be detected optically with normal CPC optics, a booster CPC is used to grow and count the particles. Downstream of the growth tube, the flow is split to the CPC $\left(1 \mathrm{~L} \mathrm{~min}^{-1}\right)$, of which flow rate is controlled by a critical orifice, and an excess flow, which is controlled by a mass flow controller. The excess flow rate varies from 2.6 to $3.5 \mathrm{~L} \mathrm{~min}^{-1}$ depending on the saturator flow rate in order to keep the inlet sampling flow rate constantly at $2.5 \mathrm{~L} \mathrm{~min}^{-1}$. By varying the saturator flow rate, it is possible to change the supersaturation and measure size distributions in the size range of 1 to $2.5 \mathrm{~nm}$. The inversion routine for the nCNC is presented by Lehtipalo et al. (2014), and the inversion routine has been experimentally verified by Kangasluoma et al. (2015). Vanhanen et al. (2011) reported a theoretical prediction of the maximum supersaturation in the mixing region at a mixing ratio of 0.1 , whereas their experiments showed that supersaturation continued to increase at mixing ratios larger than 0.1 . The mixing ratio in the PSM is defined as $Q_{\text {saturator }} /\left(Q_{\text {aerosol }}+Q_{\text {saturator }}\right)$, where $Q$ indicates a volume flow rate of a given flow. In our study the observation of Vanhanen et al. (2011) is experimentally explained by two different regions of supersaturation inside the PSM.

In this technical study, we concentrate on the challenges which can be encountered when doing field measurements with the Airmodus nCNC system, and we propose solutions for them. The studied problems are related to (1) the effect of the inlet line pressure on the flow rates of the nCNC, (2) the heterogeneous nucleation of DEG inside the PSM and (3) the sampling of very small particles. We identify two different supersaturation regions inside the PSM and show that the nCNC can be used to measure size distributions of particles in the size range between 1 and $6 \mathrm{~nm}$. The increased measurement capability is achieved by varying the temperature of the growth tube inside the PSM at constant flow rates, eliminating the need of mass flow controllers and changing flow dynamics. We also illustrate how to select suitable temperatures and flow rates inside the PSM to achieve an optimal performance. However, the exact temperatures and conditions used in this work do not directly apply to each and every PSM or to all possible experiments. This is due to the 


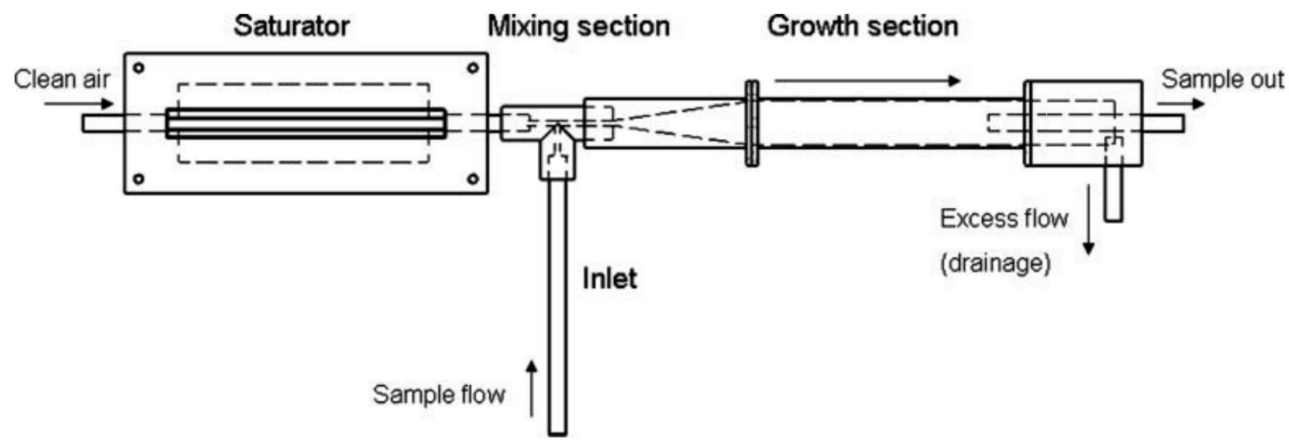

Figure 1. A schematic figure of the Particle Size Magnifier (PSM) (reproduced from Vanhanen et al., 2011).

fact that there are variations in the calibrations of temperature sensors, in particle composition and in relative humidity of the sample flow, all of which can have effects on the PSM activation efficiency. Thus, we only want to underline some of the challenges and provide some first-order solutions. Finally, we introduce and describe a sampling inlet line that is found to improve the performance of the instrument during long-term field measurements, and which can be used to filter small ions from the sample.

\section{Experiments}

Following Stolzenburg and McMurry (1991), the total detection efficiency of the $\mathrm{nCNC}$ is given by an equation:

$\varepsilon_{\mathrm{nCNC}}=\varepsilon_{\mathrm{p} \_\mathrm{PSM}} \cdot \varepsilon_{\mathrm{a} \_\mathrm{PSM}} \cdot \varepsilon_{\mathrm{p} \_\mathrm{CPC}} \cdot \varepsilon_{\mathrm{a} \_} \mathrm{CPC} \cdot \varepsilon_{\mathrm{c} \_\mathrm{CPC}}$,

where $\varepsilon_{\mathrm{p} \_ \text {PSM }}$ is penetration through the PSM, $\varepsilon_{\mathrm{a} \_ \text {PSM }}$ is the activation efficiency of the PSM, $\varepsilon_{\mathrm{p} \_} \mathrm{CPC}$ is the penetration through the CPC and the line between the PSM and the CPC, $\varepsilon_{\mathrm{a} \_ \text {CPC }}$ is the activation efficiency of the CPC and $\varepsilon_{\mathrm{c} \_\mathrm{CPC}}$ is the counting efficiency of the CPC. Usually $\varepsilon_{\mathrm{nCNC}}$ is called "detection efficiency" of the nCNC, which is the term we use here. In our experiments, when an nCNC calibration is conducted, the concentration detected by the nCNC is compared to a concentration measured by an aerosol electrometer (TSI 3068B) with the same sampling line length and flow rate, thus assumed identical losses in the sampling line, and therefore the total detection efficiency, $\varepsilon_{\mathrm{nCNC}}$, is directly measured.

\subsection{The effect of low pressure}

We probed the pressure dependency of heterogeneous nucleation of DEG inside the PSM by lowering the pressure of the sample flow rate with a needle valve upstream of the nCNC. To simulate operation of the $\mathrm{nCNC}$ at high altitudes we measured down to a pressure of $50 \mathrm{kPa}$, which corresponds approximately to $5600 \mathrm{~m}$ in altitude. To obtain the pressure dependency of the nCNC inlet flow rate, two TSI mass flow meters (model 4043) were located upstream and downstream of a needle valve, which was placed in the inlet line of the nCNC. The flow rates were constant with the accuracy of the flow meters, $\pm 0.01 \mathrm{~L} \mathrm{~min}^{-1}$, and thus were manually taken from the screen of the flow meter. Additionally, the flow rates were calculated by taking into account that the saturator and excess flow rate inside the PSM are controlled by mass flow controllers. The mass flow controllers are calibrated to $293 \mathrm{~K}$, and our standard conditions for temperature and pressure (STP conditions) refer to a temperature of $293 \mathrm{~K}$ and pressure of $101325 \mathrm{~Pa}$. The pressure-corrected flow rates were calculated by

$Q_{\mathrm{STP}}=Q_{0} \cdot p_{0} / p_{\mathrm{STP}}$,

where $Q_{\mathrm{STP}}$ is the flow rate at atmospheric pressure $\left(p_{\mathrm{STP}}\right)$ and $Q_{0}$ is the flow rate at low pressure $p_{0}$. The volumetric inlet flow rate of the $\mathrm{CPC}$, nominally $1.07 \mathrm{~L} \mathrm{~min}^{-1}$, was observed to remain constant also at low pressure down to $50 \mathrm{kPa}$, since it was controlled with a critical orifice, which maintains the flow rate at our operation conditions. From the three flows rates of the $\mathrm{nCNC}$, the inlet flow rate at STP conditions is given by

$Q_{\text {inlet_STP }}=Q_{\text {excess }}+Q_{\text {STP_CPC }}-Q_{\text {saturator }}$,

and the pressure corrected inlet flow rate at low pressure is given by

$Q_{\text {inlet_pressure_corrected }}=Q_{0 \_ \text {excess }}+Q_{\mathrm{CPC}}-Q_{0 \_ \text {saturator }}$,

where the subscript " 0 " denotes the flow rate at the low pressure calculated by Eq. (2).

These two inlet flow rates were compared to the measured inlet flow rates at low pressure and in standard conditions.

To probe the effect of the nCNC inlet line pressure on the detected concentration, we generated $50 \mathrm{~nm}$ ammonium sulfate particles with an atomizer and a Hauke-type differential mobility analyzer (DMA). The pressures inside the electrometer, the nCNC and the PSM saturator were adjusted with the needle valve in the sampling line by restricting the flow (Fig. 2a). A tube, branching off the sampling line, was connected to the connector to which the DEG fill bottle is normally connected to. This was done to equilibrate the pressure 

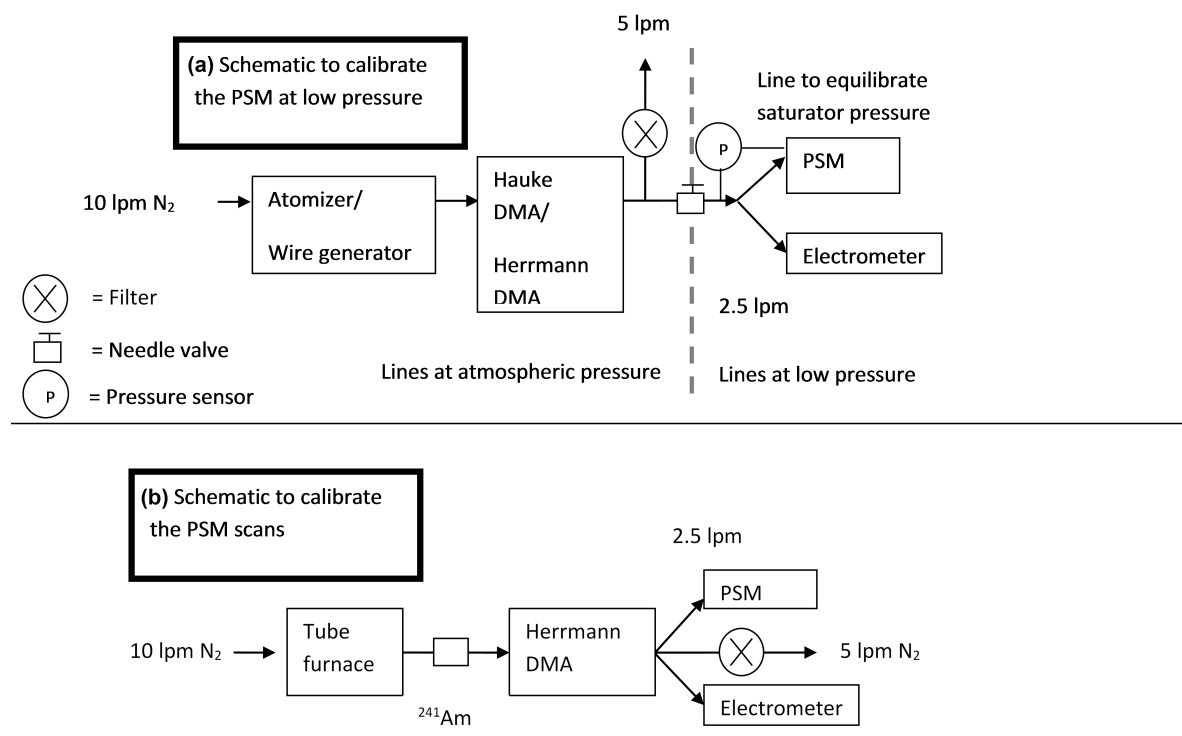

$2.5 \mathrm{lpm}$

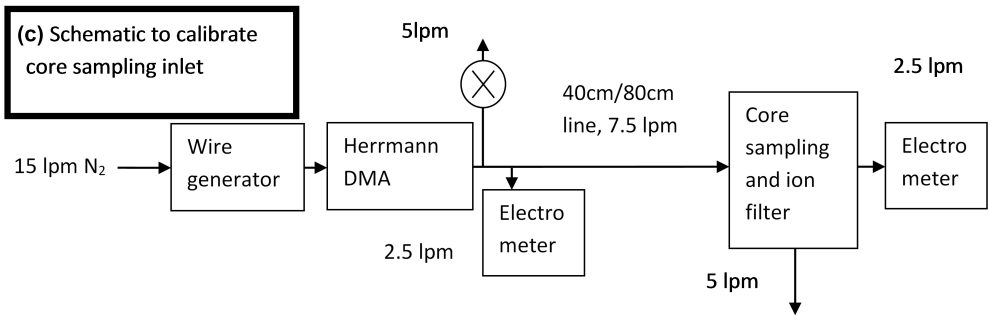

Figure 2. Schematic figures of the utilized experimental setups corresponding to different characterization experiments (a, b, c).

inside the PSM saturator to the same pressure as the inlet line pressure. The fill bottle was not used in our experiments, since higher ambient pressure deforms the bottle when the sampling line is at low pressure. As the saturator was filled with DEG before the experiments, the absence of the fill bottle should not affect the results. The concentration measured by the $\mathrm{nCNC}$ was compared to the concentration measured by the electrometer at pressures from 50 to $100 \mathrm{kPa}$. As the detection efficiency of the nCNC at low pressure can be affected by changes in the operation of the PSM or the CPC, the CPC detection efficiency alone was measured as a function of pressure. These two experiments allowed us to quantify and separate the changes in the detection efficiency of the $\mathrm{nCNC}$ caused by the PSM and the CPC.

The effect of the inlet line pressure on the $50 \%$ cut-off (diameter where $50 \%$ of the particles are detected) diameter of the $\mathrm{nCNC}$ was measured at 60,80 and $100 \mathrm{kPa}$ by generating negatively charged tungsten oxide particles from 1 to $3 \mathrm{~nm}$ (Kangasluoma et al., 2015), which were size-classified with a Herrmann-type DMA (Kangasluoma et al., 2016) (Fig. 2a).

\subsection{Operation temperatures}

The PSM can be operated in two modes: in a laminar activation mode or in a mixing activation mode. We define these modes based on the process which is driving the particle activation. By changing the temperature set points of the inlet, saturator and growth tube, it is possible to determine where the highest supersaturation of DEG takes place. If the highest supersaturation is in the mixing zone, the PSM is operated in the mixing activation mode as the supersaturation is assumed to take place due to turbulent mixing of the saturator and inlet flows. When the peak supersaturation occurs inside the growth tube, the PSM is operated in the laminar flow mode as the supersaturation is assumed to take place in the growth tube due to faster diffusion of heat than DEG. An example of a temperature setting that would allow the PSM to operate in laminar activation mode is the saturator at $85^{\circ} \mathrm{C}$, the inlet at $35^{\circ} \mathrm{C}$ and the growth tube at $5^{\circ} \mathrm{C}$. To operate the PSM in the mixing activation mode, a possible temperature setting is the saturator at $76^{\circ} \mathrm{C}$, the inlet at $0{ }^{\circ} \mathrm{C}$ and the growth tube at $40^{\circ} \mathrm{C}$. To characterize the PSM with these different temperature settings, particles from 1.1 to $2.4 \mathrm{~nm}$ were generated with an oven by heating ammonium sulfate (Kangasluoma et al., 2013) and the particles were size-classified with the Herrmann-type DMA. While size-selecting particles of nine different mobility diameters, the saturator flow rate of the PSM was scanned from 0.1 to $1 \mathrm{~L} \mathrm{~min}^{-1}$ (Fig. 2b), and the 
concentration measured by the $\mathrm{nCNC}$ was compared to the concentration measured by the electrometer.

However, the operation modes of the PSM are not completely controlled by the controlled temperature settings. Activation of the particles in the mixing region can happen, for example, when the sample air is very cold. In this case, a large temperature difference between the inlet flow and the saturator flow occurs since the heat conditioning of the inlet does not equilibrate the flow temperature perfectly to the set point temperature, which is known from simulations. This leads to cases when the activation of particles in the mixing region can happen even if the PSM is set to operate in the laminar activation mode. In practice, in some ambient conditions, for example when the sample air is very cold, the activation of particles in the mixing region is unintentionally reached in the PSM. When that happens, the supersaturation experienced by the entering particles might not be monotonically increasing with the increasing saturator flow rate, making it difficult to perform a well-established inversion of the data. We conducted an experiment that demonstrates the problem: tetraheptylammonium bromide $\left(\mathrm{C}_{28} \mathrm{H}_{60} \mathrm{NBr}\right.$, THABr) positively charged monomer (Ude and Fernández de la Mora, 2005) was guided into the $\mathrm{nCNC}$ at room temperature $\left(23^{\circ} \mathrm{C}\right)$, and the inlet temperature was varied from 0 to $40^{\circ} \mathrm{C}$ to simulate a strongly varying inlet flow rate temperature. The temperature of the saturator was set to $82^{\circ} \mathrm{C}$ and the temperature of the growth tube to $1{ }^{\circ} \mathrm{C}$ during this experiment. Under the same conditions, the concentration of the homogeneously nucleated droplets was measured when no sample particles were entering the nCNC.

During the laminar activation mode operation, the activation efficiency of the particles is governed mostly by the temperature difference between the saturator and the growth tube. Therefore, we tested the range of cut-off sizes of the nCNC by scanning the growth tube temperature, instead of scanning the saturator flow rate. The test particles were negatively charged particles produced by heating of ammonium sulfate. In the experiments, the temperature of the growth tube was set to $1{ }^{\circ} \mathrm{C}$ and other temperatures so that the activation efficiency of $1 \mathrm{~nm}$ particles was $30 \%$ at saturator flow rate of $1 \mathrm{~L} \mathrm{~min}^{-1}$. Thereafter we increased the temperature of the growth tube up to $33^{\circ} \mathrm{C}$ to find out the maximum cut-off size.

\subsection{Sampling inlet system}

The sampling line system consists of a blower and two three-way valves, which control the direction of the air flow (Fig. 3a), and a core sampling probe (Fig. 3b). The inlet system was built into a Swagelok $10 \mathrm{~mm}$ cross (ion filter) and a T-piece (core sampling). The brass electrodes of the ion filter were insulated from the Swagelok connector by polyoxymethylene housing, of which dimensions were selected so that the distance between the electrodes was $9 \mathrm{~mm}$. The dimensions and flow rates in the inlet are given in Fig. $3 \mathrm{~b}$.
By switching the valves, the air flow can be directed to the core sampling probe in either direction. If the air is drawn to the core sampling probe from the inlet, the inlet flow rate of the sampling system is increased to $7.5 \mathrm{~L} \mathrm{~min}^{-1}$, minimizing the diffusion losses. The losses of the small particles are minimized, since the particles close to the walls are lost most efficiently due to Brownian motion, while the highest concentration is in the middle line of the flow, from where the sample is extracted to the nCNC. If the bypass flow is reversed and the air is pushed to the core sampling probe, the background concentration reading of the $\mathrm{nCNC}$ can be measured, since the air coming from the inlet system is particlefree. The sampling line of the inlet system also contains an automatic on/off electric field, which filters the smallest incoming ions, allowing only neutral particles below a certain size to be sampled. The potential between the electrodes was $1300 \mathrm{~V}$. The valve switching is made automatic so that in the field experiments the background concentration detected by the $\mathrm{nCNC}$ can be measured at given time intervals for a given time period, and the ion filter can be switched on/off at a given time interval. The transmission of the sampling line was characterized by generating negatively charged tungsten oxide particles in the size range from 1.1 to $6.5 \mathrm{~nm}$ with concentrations between 2000 and $11000 \mathrm{~cm}^{-3}$, with the instrumental setup shown in Fig. 2c. Using the same test aerosol, the ion filter was tested by switching the electric field on and off.

\section{Results and discussion}

\subsection{The effect of low pressure}

The measured and modeled $\mathrm{nCNC}$ flow rates are presented in Fig. 4 as a function of inlet line pressure. The measured inlet flow rates were well reproduced by the calculated flow rates, suggesting that the flow rates of the $\mathrm{nCNC}$ at various inlet line pressures can be predicted. Understanding the $\mathrm{nCNC}$ inlet flow rate dependency on pressure helps the operation of the $\mathrm{nCNC}$ at pressures lower than the ambient pressure.

The detection efficiency of the nCNC for $50 \mathrm{~nm}$ ammonium sulfate particles as a function of inlet line pressure is presented in Fig. 5. The detection efficiency was scaled to 1 at normal pressure to show effects caused only due to the low pressure. The scaling was done due to the fact that the CPC usually detects $90-95 \%$ of the electrometer reading, and that a fraction of the mobility selected particles were larger than $50 \mathrm{~nm}$ with more than one charge, which lowered the apparent detection efficiency at normal pressure. The CPC counting efficiency correction was measured without the PSM separately against the electrometer. The sample flow of the PSM becomes diluted in the mixing zone by the saturator flow, and the dilution factor $\left(Q_{\text {inlet }} /\left(Q_{\text {inlet }}+Q_{\text {saturator }}\right)\right)$ changed as a function of the pressure. This is due to the larger increase of the inlet flow rate than the saturator flow rate with 

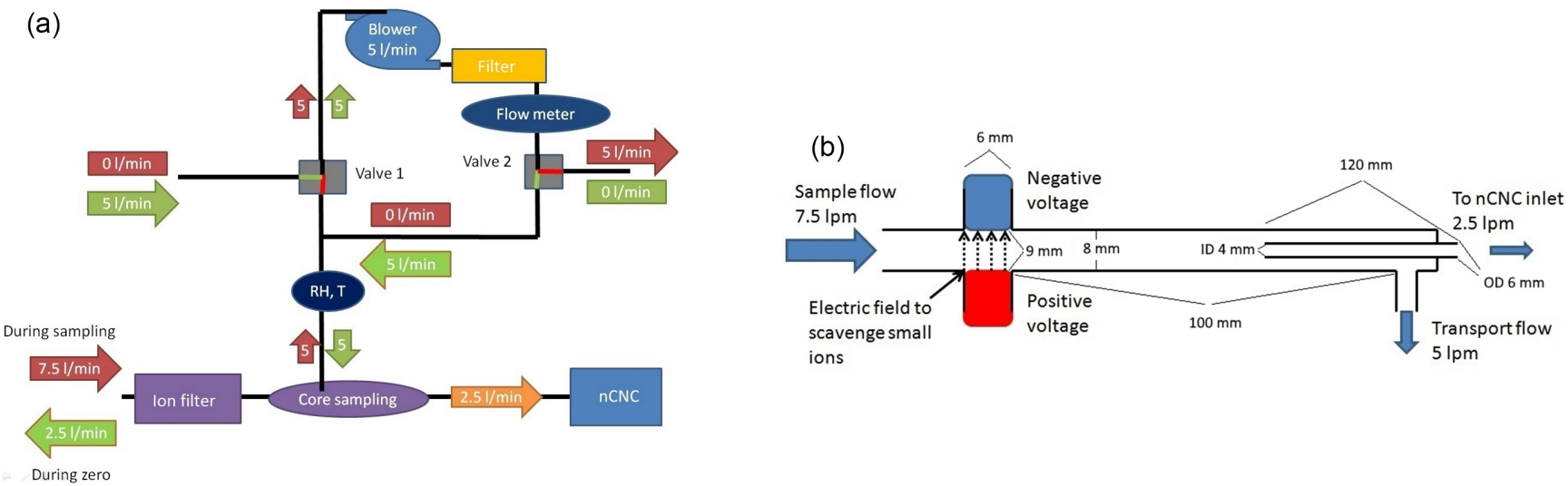

Figure 3. Schematic of the inlet system. The upper panel (a) presents the flow schematics, the lower panel (b) presents the schematic of the core sampling and ion filter arrangement. The given dimensions are not in scale in the figure.

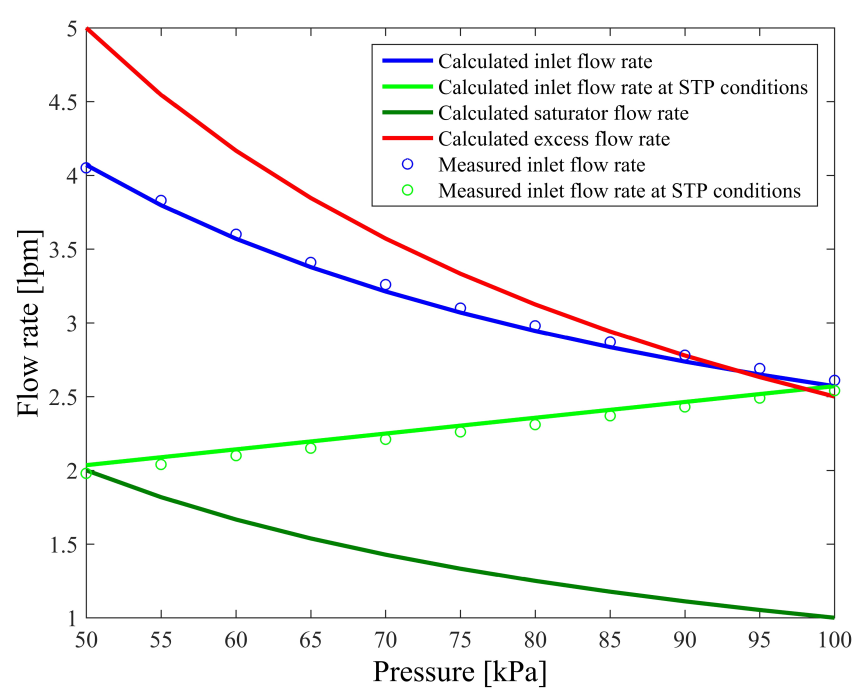

Figure 4. Calculated and measured nCNC flow rates as a function of the inlet pressure.

lowering pressure. In addition, the detection efficiency of the CPC was lower at lower pressure, probably due to the changed flow dynamics which defocuses the sample beam from the laser, changed final droplet size in the optics or changed supersaturation field in the condenser. Within the current experiments we did not solve the cause for this observation. Similar results have been obtained for example by Hermann and Wiedensohler (2001) and by Takegawa and Sakurai (2011), with the difference that the detection efficiency of the TSI 7610 and TSI 3771, respectively, decreased at pressures lower than 30 and $60 \mathrm{kPa}$, respectively. At an inlet pressure of $60 \mathrm{kPa}$ the calculated dilution correction, compared to that of $100 \mathrm{kPa}$, increased by $5.7 \%$. The CPC undercounted by approximately $10 \%$, giving a correction factor of 1.15 to the detected concentration at $60 \mathrm{kPa}$. Almost no correction was needed at pressures of $80 \mathrm{kPa}$ or higher.

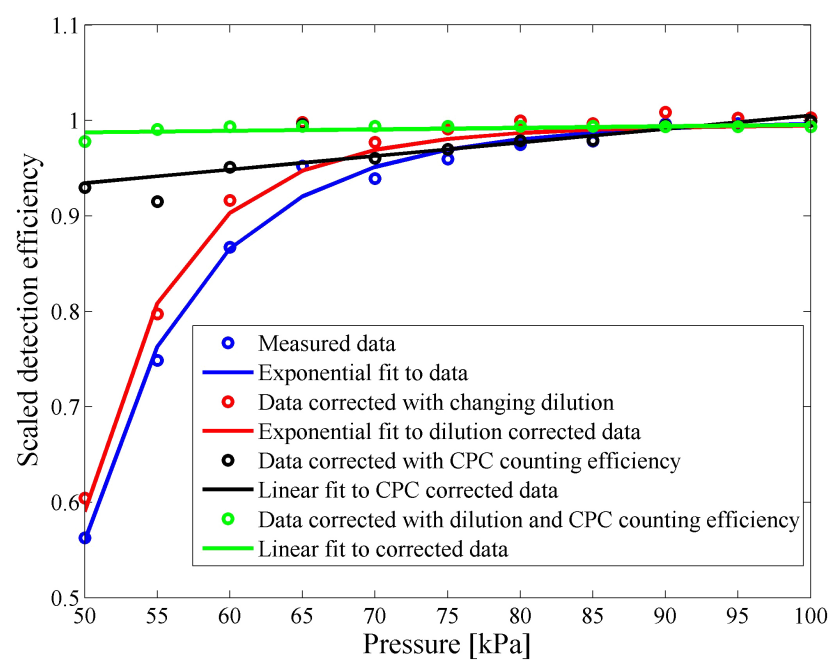

Figure 5. The detection efficiency of the nCNC measured at different pressures for $50 \mathrm{~nm}$ ammonium sulfate particles. The blue circles are the uncorrected data, the red data were corrected with the calculated dilution correction, the black data were corrected for the CPC under-counting and the green data were corrected for both effects. Curves have been normalized to unity at normal pressure to separate the two corrections. Green data points can only be reached by correcting the measured data with these two corrections.

The detection efficiency of the nCNC for negatively charged tungsten oxide particles at PSM settings $T_{\text {sat }}=$ $75^{\circ} \mathrm{C}, T_{\text {inlet }}=35^{\circ} \mathrm{C}$ and $T_{\mathrm{gt}}=4^{\circ} \mathrm{C}$ is presented in Fig. 6 at pressures of 60,80 and $100 \mathrm{kPa}$. The detection efficiency curves were scaled to unity at $3 \mathrm{~nm}$ to explore the effect of the pressure on the cut-off diameter. The detection efficiency is still increasing at $3 \mathrm{~nm}$ due to the not completely uniform supersaturation field experienced by the particles in the PSM and CPC. Uncertainty of the detection efficiency has been estimated as 1 standard deviation of the measured concentration, and uncertainty of the mobility diameter has been esti- 


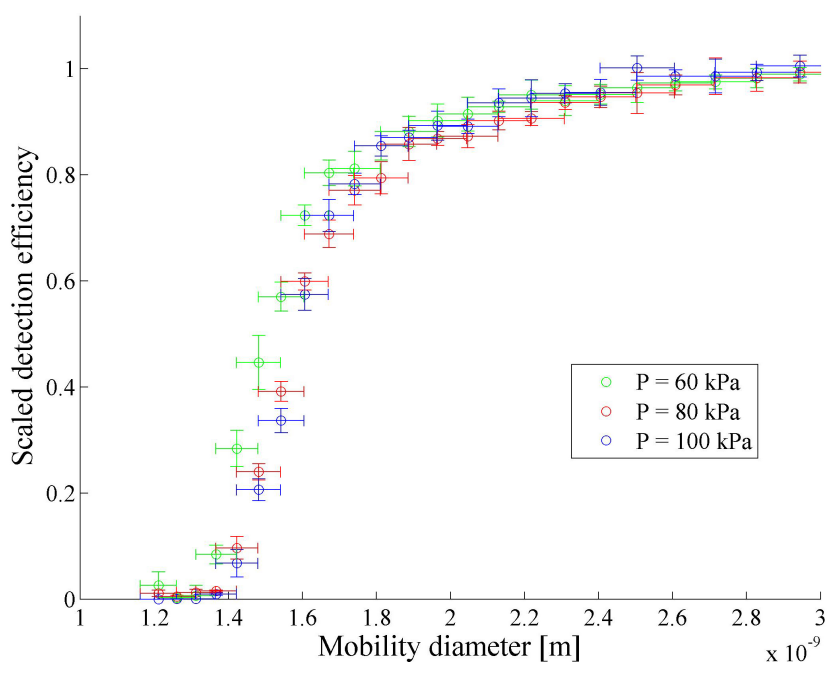

Figure 6. The detection efficiency of the $\mathrm{nCNC}$ as a function of the mobility diameter for negatively charged tungsten oxide particles at pressures of 60,80 and $100 \mathrm{kPa}$.

mated as the full width of half maximum of the DMA transfer function, $4 \%$. With these settings, the cut-off diameters were $1.55,1.60$ and $1.60 \mathrm{~nm}$ respectively. The change in the cutoff diameter can be explained by the changed dilution factor, which increased the supersaturation slightly at lower pressure, compared to the case when the inlet line was at ambient pressure. The change was rather small given the uncertainties in the cut-off diameter, which are due to the particle chemical composition (Kangasluoma et al., 2014).

\subsection{Operation temperatures}

In our study we confirmed the calculation presented in Vanhanen et al. (2011), which predicted the peak supersaturation to occur at mixing ratio of 0.1 in the mixing zone. The calibration of the $\mathrm{nCNC}$ in the mixing activation mode is presented in Fig. 7 and, for comparison, a calibration in the laminar activation mode is presented in Fig. 8. The temperature settings mentioned above in mixing activation mode led to the onset supersaturation of homogeneous nucleation at saturator flow rates of $0.3-0.7 \mathrm{~L} \mathrm{~min}^{-1}$. As modeled in Vanhanen et al. (2011), the maximum supersaturation should occur at a mixing ratio of approximately 0.1 and become lower at higher mixing ratios. A mixing ratio of 0.1 corresponds to a saturator flow rate of $0.28 \mathrm{~L} \mathrm{~min}^{-1}$ and was reproduced by the experiments, as the maximum detection efficiency for the smallest particles was observed at saturator flow rate of approximately $0.3 \mathrm{~L} \mathrm{~min}^{-1}$. The lower supersaturation at the saturator flow rates of larger than $0.3 \mathrm{~L} \mathrm{~min}^{-1}$ was also observed. However, with particles larger than $1.4 \mathrm{~nm}$ the maximum detection efficiency shifted towards larger saturator flow rates for reasons that we cannot yet explain.

If the PSM was operated in the mixing activation mode, the maximum detection efficiency for particles smaller than

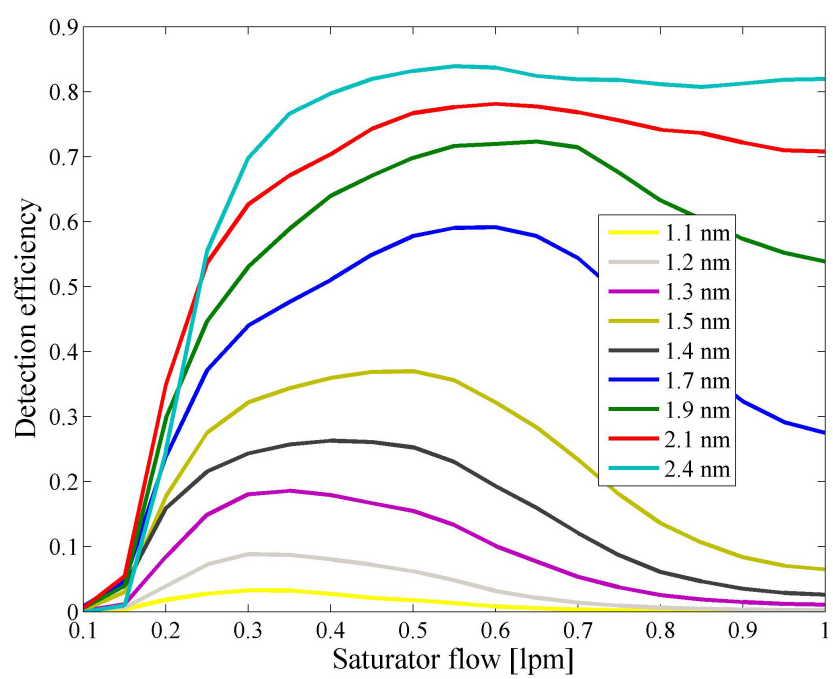

Figure 7. The detection efficiency of the nCNC for negatively charged particles formed during heating of ammonium sulfate, when the PSM was operated in mixing activation mode.

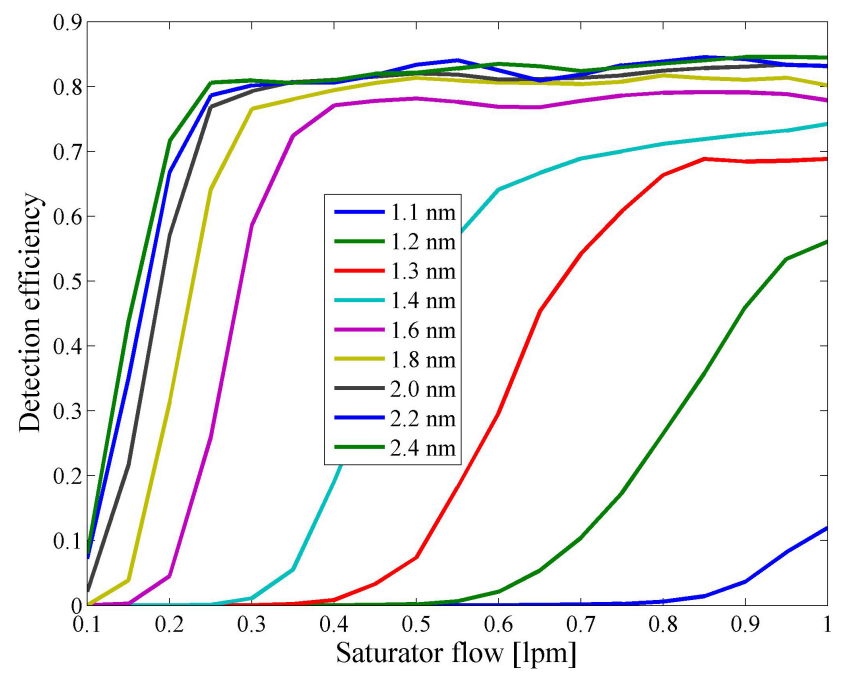

Figure 8. The detection efficiency of the nCNC for negatively charged particles formed during heating of ammonium sulfate, when the PSM was operated in laminar activation mode.

$1.5 \mathrm{~nm}$ was rather low. Moreover, the shape of the detection efficiency curve as a function of saturator flow rate was changing. In the conventional laminar activation mode the PSM detection efficiency increased monotonically with increasing saturator flow rate. This is due to the fact that the supersaturation in the growth tube increases with increasing saturator flow rate. For these reasons we suggest operating the PSM in laminar activation mode for the easier inversion of data, as presented in Lehtipalo et al. (2014).

To activate the THABr positive monomer with a high efficiency with DEG, a supersaturation exceeding the limit of homogeneous droplet formation is required. It is important 


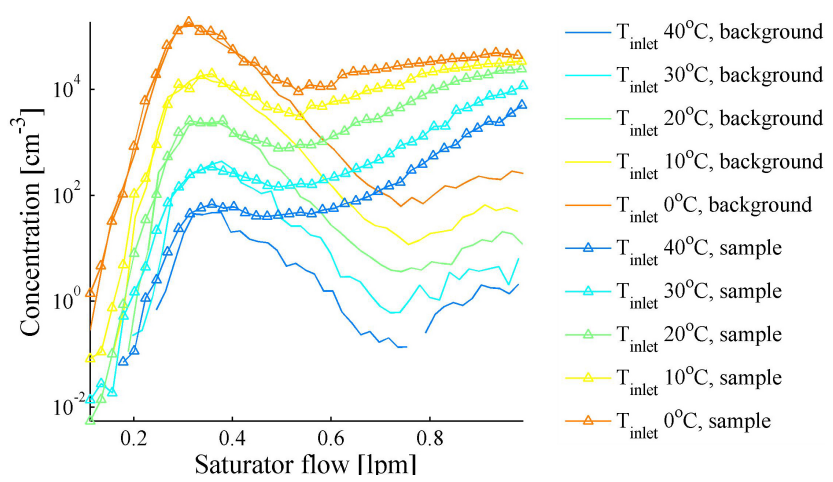

Figure 9. Concentration of homogeneously nucleated droplets (background) and detected concentration of positively charged THABr monomer (sample) at equal supersaturation. Concentration peak at saturator flow rate $0.3 \mathrm{~L} \mathrm{~min}^{-1}$ can be attributed to high supersaturation in the mixing region, while detection of $\mathrm{THABr}$ monomer at larger saturator flow rates than $0.3 \mathrm{~L} \mathrm{~min}^{-1}$ can be attributed to high supersaturation in the growth tube.

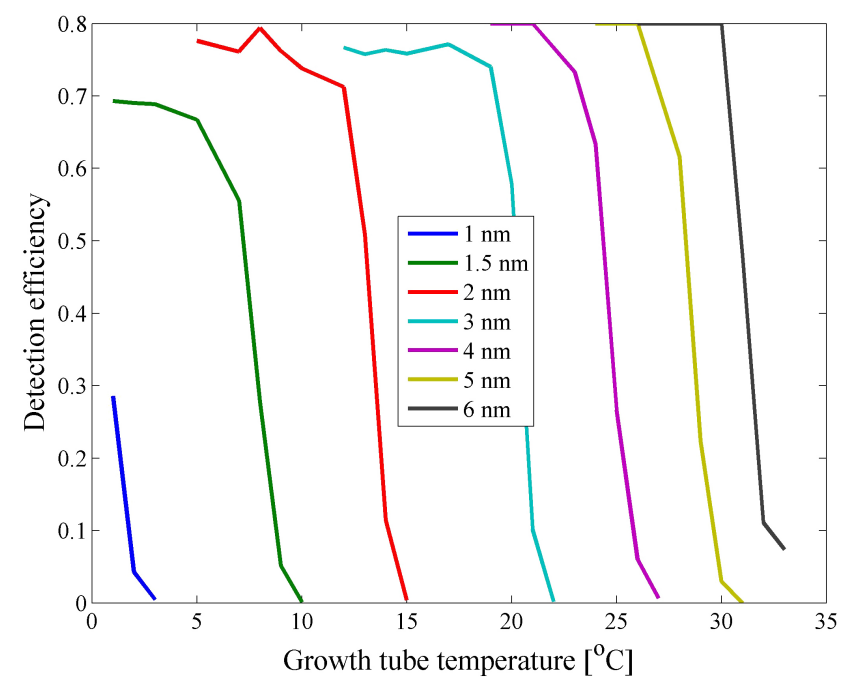

Figure 10. The detection efficiency of the $\mathrm{nCNC}$ for various sizes of negatively charged particles formed during heating of ammonium sulfate as a function of the growth tube temperature.

to note that a high saturator temperature leads to a large temperature difference between the saturator and the inlet, when the PSM is operated in the laminar activation mode. This high temperature difference can enable activation of particles in the mixing chamber, as shown in Fig. 9 (high concentrations at saturator flow rate of $0.3 \mathrm{~L} \mathrm{~min}^{-1}$ ). The lower the inlet temperature, the higher the concentration of homogeneously formed droplets in the mixing region became. Notably, the inlet temperature influenced the flow temperature and the supersaturation in the growth tube. In addition, the activation efficiency increased in the growth tube with lower inlet temperatures. At a saturator flow rate of $1 \mathrm{~L} \mathrm{~min}^{-1}$, we observed an increase in the detection efficiency from 10 to

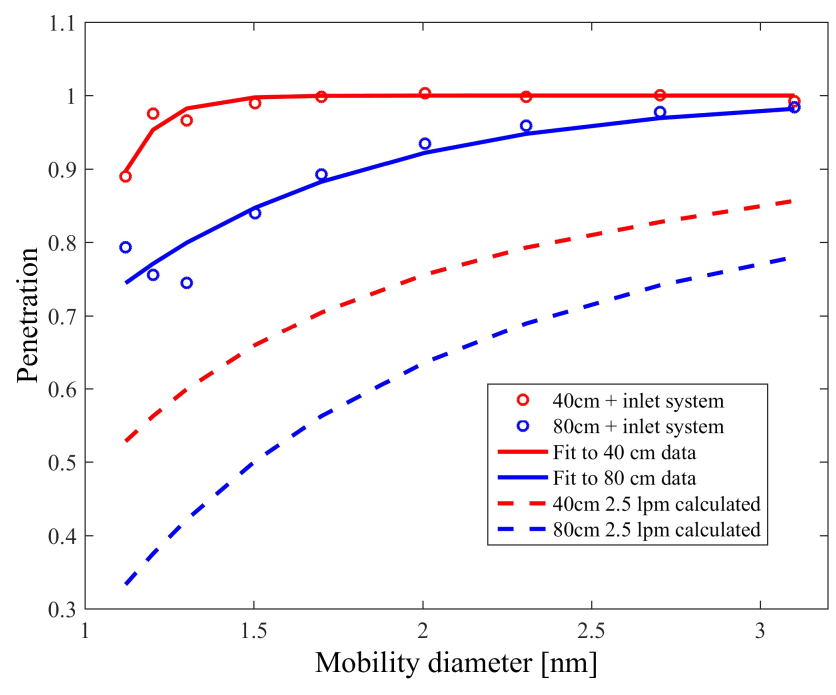

Figure 11. Measured particle penetration efficiency as a function of mobility diameter through the new inlet system (dots) with fitted lines to guide the eye. Dashed lines are calculated penetration efficiencies according to the Gormley and Kennedy equation for equal line lengths with $2.5 \mathrm{~L} \mathrm{~min}^{-1}$ flow rate (nCNC inlet flow rate).

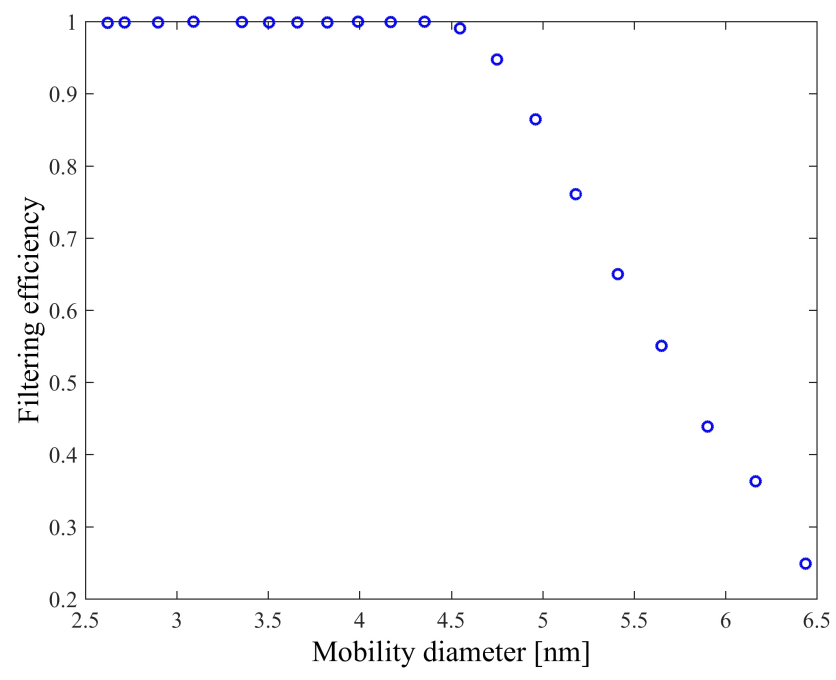

Figure 12. Measured ion filtering efficiency of the new sampling system as function of the mobility diameter.

$50 \%$ when the temperature of the inlet was decreased from 40 to $0^{\circ} \mathrm{C}$, resulting in a decrease in the cut-off diameter of approximately $0.2 \mathrm{~nm}$. The illustrated background concentration is likely to appear only if the PSM is operated at supersaturations high enough to produce homogeneous nucleation of DEG, which is required to detect some organic particles smaller than $2 \mathrm{~nm}$ particles at detection efficiency higher than $10 \%$ (Kangasluoma et al., 2014; Kuang et al., 2012b). Based on these experiments, we suggest keeping the temperature of the inlet as high as still suitable for the experiment (current firmware maximum $40^{\circ} \mathrm{C}$ ), keeping the temperature of the 


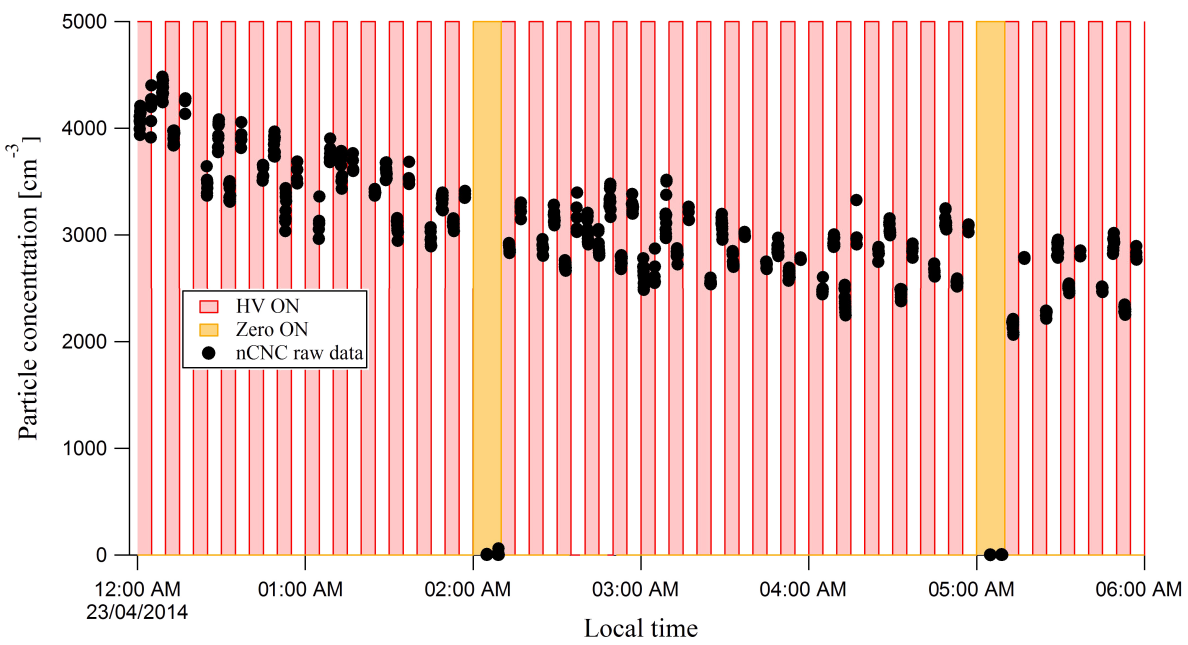

Figure 13. Time series of particle concentration measured in Hyytiälä, Finland, with the nCNC and new inlet system. The red background (HV ON) color indicates the time when the ion filter in the inlet system is on. The yellow background (ZERO ON) color indicates the time when the automatic background concentration measurement is conducted. Changes in the concentration measured by the nCNC can be attributed to the removal of ions from the sample flow when the ion filter is on and the measurement of particle-free air when the background concentration is measured.

growth tube as low as possible (firmware minimum $1{ }^{\circ} \mathrm{C}$ ) and adjusting the supersaturation by changing the temperature of the saturator. This way the temperature difference between the inlet and the saturator is minimized. At a saturator flow rate of $0.3 \mathrm{~L} \mathrm{~min}^{-1}$, a high enough supersaturation was observed to produce homogeneously nucleated particles, which however, was not observed to activate any particles. Simultaneously, at a saturator flow rate of $1 \mathrm{~L} \mathrm{~min}^{-1}$ (laminar-type activation), the concentration of homogeneously nucleated droplets inside the instrument is usually a good indication of activation efficiency (Jiang et al., 2011). This observation suggests some processes in the mixing zone that are not understood properly.

We conducted an experiment to investigate the change in the nCNC cut-off by varying the growth tube temperature instead of by changing the flow rate of the saturator (Fig. 10). We found that it is possible to vary the cut-off size from 1 to $6 \mathrm{~nm}$. Thus, scanning the growth tube temperature would allow the measurement of a wider particle size range without the change of flow rates. With the current hardware, we estimate that the time resolution of the temperature scan would be around 7 to $10 \mathrm{~min}$.

\subsection{Sampling inlet}

Here we describe the performance of a new sampling inlet, which can be used to reduce sampling line losses, and to perform automated zero measurements and optionally filter ions from the sample. The sampling inlet is useful, especially during field campaigns and long-term measurements, during which zero measurements should be conducted to particle counters at regular intervals to monitor their performance and to be able to remove the possible background counts from the data. Filtering of small ions from the data can be useful for certain applications of the instrument, e.g., calculating the ion fractions of small particles for new particle formation studies.

By adding $5 \mathrm{~L} \mathrm{~min}^{-1}$ as a bypass flow to the $\mathrm{nCNC}$ inlet flow rate and subsampling from the center line of the long tube, the $\mathrm{nCNC}$ was able to sample $40 \mathrm{~cm}$ away from the inlet without major losses of the smallest particles (Fig. 11). This is ideal when using the nCNC in field experiments. Doubling the sampling line length to $80 \mathrm{~cm}$ increased the diffusion losses of the particles, as the particles had more time to diffuse away from the middle of the flow. The inlet system increased the sampling efficiency by a factor of 1.5 to 2 compared to a penetration calculated using the Gormley and Kennedy equation (Gormley and Kennedy, 1949) at a flow rate of $2.5 \mathrm{~L} \mathrm{~min}^{-1}$ and through an $80 \mathrm{~cm}$ tube. For our calculations, we used an inlet flow rate of $2.5 \mathrm{~L} \mathrm{~min}^{-1}$ to simulate the case when no core sampling inlet was utilized and the inlet line was a straight tube with no additional flow. When the electric field was switched on, a complete removal of ions smaller than $4.5 \mathrm{~nm}$ was observed (Fig. 12). By varying the strength of the electric field, the size of the largest removed ion could be varied (not shown).

The zero measurements and ion filtering can be automated using the new inlet, as shown in Fig. 13. When the inlet switches to measure particle-free air, only the background counts resulting from homogenous nucleation are detected. When the automatic ion filter is switched on and off, a change in the detected particle concentration is observed (Fig. 13), which can be attributed to the removal of the ions from the sample flow. 
Table 1. Brief compilation of challenges and solutions explored in this study.

\begin{tabular}{ll}
\hline Challenge & Solution \\
\hline Varying inlet pressure & $\begin{array}{l}\text { Depending on the application, variations in the cut-off diameter can be neglected. The measured } \\
\text { concentration needs to be corrected with the pressure-dependent dilution correction and CPC } \\
\text { undercounting if the pressure is smaller than } 80 \mathrm{kPa} .\end{array}$ \\
\hline $\begin{array}{l}\text { M-shaped scans in field } \\
\text { measurements }\end{array}$ & $\begin{array}{l}\text { Caused by homogeneous/heterogeneous nucleation occurring in the mixing zone instead of the } \\
\text { growth tube. Decrease growth tube temperature to minimum and maximize inlet temperature to } \\
\text { minimize dT between the inlet and saturator. Adjust saturator temperature for suitable activation } \\
\text { efficiency. }\end{array}$ \\
\hline $\begin{array}{l}\text { Low penetration of small } \\
\text { particles in a sampling line, } \\
\text { automatized measurement of } \\
\text { sub-5 nm charged fraction and } \\
\text { background concentration. }\end{array}$ & $\begin{array}{l}\text { Core sampling inlet system with a bypass flow, on/off ion filter and a flow system to automatize } \\
\text { background measurement (Fig. 3). }\end{array}$ \\
\hline
\end{tabular}

\section{Conclusions}

In the current study, we explored the characteristics of the Airmodus A11 nCNC instrument in challenging conditions. The challenges and suggested solutions are listed in Table 1. Our results show that, when operated at low pressure, the nCNC underestimated the real aerosol number concentration due to the changes in the flow rates inside the PSM and due to the CPC undercounting. We showed that at a given flow rate and temperature conditions, the PSM activates particles in the growth tube like a laminar-type CPC, but can be converted into a mixing-type $\mathrm{CPC}$ by changing the temperature set points. By understanding how supersaturation in the PSM is related to the temperatures and flow rates, we reproduced a problem observed in some field experiments, where particles are activated in the mixing region simultaneously with the activation of particles in the growth tube. This interference makes it difficult to invert the data and to retrieve sizeclassified particle concentration information. For an optimal operation, we suggest keeping the growth tube temperature as low as possible (firmware minimum $1^{\circ} \mathrm{C}$ ) and the inlet temperature as high as possible (firmware maximum $40^{\circ} \mathrm{C}$ ), to achieve the required supersaturation with as low a saturator temperature as possible. The procedure minimizes the temperature difference between the inlet and the saturator, and minimizes the possibility of forming homogeneously nucleated droplets in the mixing region. We showed that by scanning the growth tube temperature, the PSM can potentially measure size distributions up to $6 \mathrm{~nm}$. Finally, with a proper design of the sampling inlet, we showed how to automatize the measurement of the background concentration of the nCNC, remove ions smaller than $4.5 \mathrm{~nm}$ from the sample flow and achieve sampling line transmission of nearly $100 \%$ for particles down to $1.2 \mathrm{~nm}$ in mobility diameter through a $40 \mathrm{~cm}$ tube.
Acknowledgements. This work was partly funded by the European Research Council (ATMNUCLE, 227463), the Academy of Finland (Center of Excellence Program projects 1118615 and 139656), the Nordic Center for Excellence (CRAICC), the European Commission Seventh Framework program (ACTRIS, contract no. 262254; PEGASOS, contract no. 265148), the European Union's Horizon 2020 research and innovation program under the Marie Sklodowska-Curie (grant no. 656994), the Office of Science (BER) and the US Department of Energy (The Biogenic Aerosols - Effects of Clouds and Climate, BAECC).

Edited by: J.-P. Putaud

\section{References}

Alanen, J., Saukko, E., Lehtoranta, K., Murtonen, T., Timonen, H., Hillamo, R., Karjalainen, P., Kuuluvainen, H., Harra, J., Keskinen, J., and Ronkko, T.: The formation and physical properties of the particle emissions from a natural gas engine, Fuel, 162, 155-161, 2015.

Almeida, J., Schobesberger, S., Kurten, A., Ortega, I. K., Kupiainen-Maatta, O., Praplan, A. P., Adamov, A., Amorim, A., Bianchi, F., Breitenlechner, M., David, A., Dommen, J., Donahue, N. M., Downard, A., Dunne, E., Duplissy, J., Ehrhart, S., Flagan, R. C., Franchin, A., Guida, R., Hakala, J., Hansel, A., Heinritzi, M., Henschel, H., Jokinen, T., Junninen, H., Kajos, M., Kangasluoma, J., Keskinen, H., Kupc, A., Kurten, T., Kvashin, A. N., Laaksonen, A., Lehtipalo, K., Leiminger, M., Leppa, J., Loukonen, V., Makhmutov, V., Mathot, S., McGrath, M. J., Nieminen, T., Olenius, T., Onnela, A., Petaja, T., Riccobono, F., Riipinen, I., Rissanen, M., Rondo, L., Ruuskanen, T., Santos, F. D., Sarnela, N., Schallhart, S., Schnitzhofer, R., Seinfeld, J. H., Simon, M., Sipila, M., Stozhkov, Y., Stratmann, F., Tome, A., Trostl, J., Tsagkogeorgas, G., Vaattovaara, P., Viisanen, Y., Virtanen, A., Vrtala, A., Wagner, P. E., Weingartner, E., Wex, H., Williamson, C., Wimmer, D., Ye, P. L., Yli-Juuti, T., Carslaw, K. S., Kulmala, M., Curtius, J., Baltensperger, U., Worsnop, D. R., Vehkamaki, H., and Kirkby, J.: Molecular un- 
derstanding of sulphuric acid-amine particle nucleation in the atmosphere, Nature, 502, 359-363, 2013.

Bricard, J., Delattre, P., Madelaine, G., and Pourprix, M.: Detection of ultra-fine particles by means of a continuous flux condensation nuclei counter, Fine Particles, Academic Press, New York, 565$580,1976$.

Ehn, M., Thornton, J. A., Kleist, E., Sipilä, M., Junninen, H., Pullinen, I., Springer, M., Rubach, F., Tillmann, R., Lee, B., LopezHilfiker, F., Andres, S., Acir, I. H., Rissanen, M., Jokinen, T., Schobesberger, S., Kangasluoma, J., Kontkanen, J., Nieminen, T., Kurten, T., Nielsen, L. B., Jorgensen, S., Kjaergaard, H. G., Canagaratna, M., Maso, M. D., Berndt, T., Petäjä, T., Wahner, A., Kerminen, V. M., Kulmala, M., Worsnop, D. R., Wildt, J., and Mentel, T. F.: A large source of low-volatility secondary organic aerosol, Nature, 506, 476-479, 2014.

Gamero-Castano, M. and Fernández de la Mora, J.: A condensation nucleus counter (CNC) sensitive to singly charged subnanometer particles, J. Aerosol Sci., 31, 757-772, 2000.

Gormley, P. G. and Kennedy, M.: Diffusion from a stream flowing through a cylindrical tube, Proceedings of the Royal Irish Academy, 52, 163-169, 1949.

Hermann, M. and Wiedensohler, A.: Counting efficiency of condensation particle counters at low-pressures with illustrative data from the upper troposphere, J. Aerosol Sci., 32, 975-991, 2001.

Iida, K., Stolzenburg, M. R., and McMurry, P. H.: Effect of Working Fluid on Sub-2 nm Particle Detection with a Laminar Flow Ultrafine Condensation Particle Counter, Aerosol Sci. Tech., 43, 81-96, 2009.

Ito, E., Seto, T., Otani, Y., and Sakurai, H.: Nucleation of Ethylene Glycol Vapor and Growth of Sub-10-nm Particles in Nanoparticle Size Magnifier, Aerosol Sci. Tech., 45, 1250-1259, 2011.

Jiang, J. K., Chen, M. D., Kuang, C. A., Attoui, M., and McMurry, P. H.: Electrical Mobility Spectrometer Using a Diethylene Glycol Condensation Particle Counter for Measurement of Aerosol Size Distributions Down to $1 \mathrm{~nm}$, Aerosol Sci. Tech., 45, 510-521, 2011.

Kangasluoma, J., Junninen, H., Lehtipalo, K., Mikkilä, J., Vanhanen, J., Attoui, M., Sipilä, M., Worsnop, D., Kulmala, M., and Petäjä, T.: Remarks on Ion Generation for CPC Detection Efficiency Studies in Sub-3-nm Size Range, Aerosol Sci. Tech., 47, 556-563, 2013.

Kangasluoma, J., Kuang, C., Wimmer, D., Rissanen, M. P., Lehtipalo, K., Ehn, M., Worsnop, D. R., Wang, J., Kulmala, M., and Petäjä, T.: Sub-3 nm particle size and composition dependent response of a nano-CPC battery, Atmos. Meas. Tech., 7, 689-700, doi:10.5194/amt-7-689-2014, 2014.

Kangasluoma, J., Attoui, M., Junninen, H., Lehtipalo, K., Samodurov, A., Korhonen, F., Sarnela, N., Schmidt-Ott, A., Worsnop, D., Kulmala, M., and Petäjä, T.: Sizing of neutral sub $3 \mathrm{~nm}$ tungsten oxide clusters using Airmodus Particle Size Magnifier, J. Aerosol Sci., 87, 53-62, 2015.

Kangasluoma, J., Attoui, M., Korhonen, F., Ahonen, L., Siivola, E., and Petäjä, T.: Characterization of a Herrmann type high resolution differential mobility analyzer, Aerosol Sci. Tech., 50, 222229, 2016.

Kerminen, V.-M., Paramonov, M., Anttila, T., Riipinen, I., Fountoukis, C., Korhonen, H., Asmi, E., Laakso, L., Lihavainen, H., Swietlicki, E., Svenningsson, B., Asmi, A., Pandis, S. N., Kulmala, M., and Petäjä, T.: Cloud condensation nuclei production associated with atmospheric nucleation: a synthesis based on existing literature and new results, Atmos. Chem. Phys., 12, 1203712059, doi:10.5194/acp-12-12037-2012, 2012.

Kim, C. S., Okuyama, K., and Shimada, M.: Performance of a mixing-type CNC for nanoparticles at low-pressure conditions, J. Aerosol Sci., 33, 1389-1404, 2002.

Kim, S., Iida, K., Kuromiya, Y., Seto, T., Higashi, H., and Otani, Y.: Effect of Nucleation Temperature on Detecting Molecular Ions and Charged Nanoparticles with a Diethylene Glycol-Based Particle Size Magnifier, Aerosol Sci. Tech., 49, 35-44, 2015.

Kirkby, J., Curtius, J., Almeida, J., Dunne, E., Duplissy, J., Ehrhart, S., Franchin, A., Gagne, S., Ickes, L., Kurten, A., Kupc, A., Metzger, A., Riccobono, F., Rondo, L., Schobesberger, S., Tsagkogeorgas, G., Wimmer, D., Amorim, A., Bianchi, F., Breitenlechner, M., David, A., Dommen, J., Downard, A., Ehn, M., Flagan, R. C., Haider, S., Hansel, A., Hauser, D., Jud, W., Junninen, H., Kreissl, F., Kvashin, A., Laaksonen, A., Lehtipalo, K., Lima, J., Lovejoy, E. R., Makhmutov, V., Mathot, S., Mikkilä, J., Minginette, P., Mogo, S., Nieminen, T., Onnela, A., Pereira, P., Petäjä, T., Schnitzhofer, R., Seinfeld, J. H., Sipilä, M., Stozhkov, Y., Stratmann, F., Tome, A., Vanhanen, J., Viisanen, Y., Vrtala, A., Wagner, P. E., Walther, H., Weingartner, E., Wex, H., Winkler, P. M., Carslaw, K. S., Worsnop, D. R., Baltensperger, U., and Kulmala, M.: Role of sulphuric acid, ammonia and galactic cosmic rays in atmospheric aerosol nucleation, Nature, 476, 429-433, 2011.

Kogan, Y. I. and Burnasheva, Z. A.: Growth and Measurement of Condensation Nuclei in a Continuous Stream, Zhurnal Fizicheskoi Khimii, 34, 2630-2639, 1960.

Kontkanen, J., Lehtinen, K. E. J., Nieminen, T., Manninen, H. E., Lehtipalo, K., Kerminen, V.-M., and Kulmala, M.: Estimating the contribution of ion-ion recombination to sub-2 $\mathrm{nm}$ cluster concentrations from atmospheric measurements, Atmos. Chem. Phys., 13, 11391-11401, doi:10.5194/acp-13-11391-2013, 2013.

Kontkanen, J., Järvinen, E., Manninen, H. E., Lehtipalo, K., Kangasluoma, J., Decesari, S., Gobbi, G. P., Laaksonen, A., Petäjä, T., and Kulmala, M.: High concentrations of sub-3nm clusters and frequent new particle formation observed in the Po Valley, Italy, during the PEGASOS 2012 campaign, Atmos. Chem. Phys., 16, 1919-1935, doi:10.5194/acp-16-1919-2016, 2016.

Kuang, C., Chen, M., Zhao, J., Smith, J., McMurry, P. H., and Wang, J.: Size and time-resolved growth rate measurements of 1 to 5 $\mathrm{nm}$ freshly formed atmospheric nuclei, Atmos. Chem. Phys., 12, 3573-3589, doi:10.5194/acp-12-3573-2012, 2012a.

Kuang, C., Chen, M. D., McMurry, P. H., and Wang, J.: Modification of Laminar Flow Ultrafine Condensation Particle Counters for the Enhanced Detection of $1 \mathrm{~nm}$ Condensation Nuclei, Aerosol Sci. Tech., 46, 309-315, 2012b.

Kulmala, M., Kontkanen, J., Junninen, H., Lehtipalo, K., Manninen, H. E., Nieminen, T., Petäjä, T., Sipilä, M., Schobesberger, S., Rantala, P., Franchin, A., Jokinen, T., Järvinen, E., Äijalä, M., Kangasluoma, J., Hakala, J., Aalto, P. P., Paasonen, P., Mikkilä, J., Vanhanen, J., Aalto, J., Hakola, H., Makkonen, U., Ruuskanen, T., Mauldin, R. L., Duplissy, J., Vehkamäki, H., Bäck, J., Kortelainen, A., Riipinen, I., Kurten, T., Johnston, M. V., Smith, J. N., Ehn, M., Mentel, T. F., Lehtinen, K. E. J., Laaksonen, A., Kerminen, V. M., and Worsnop, D. R.: Direct Observations of Atmospheric Aerosol Nucleation, Science, 339, 943-946, 2013. 
Lehtipalo, K., Leppä, J., Kontkanen, J., Kangasluoma, J., Franchin, A., Wimnner, D., Schobesberger, S., Junninen, H., Petäjä, T., Sipilä, M., Mikkilä, J., Vanhanen, J., Worsnop, D. R., and Kulmala, M.: Methods for determining particle size distribution and growth rates between 1 and $3 \mathrm{~nm}$ using the Particle Size Magnifier, Boreal Environ. Res., 19, 215-236, 2014.

Mavliev, R. and Wang, H. C.: Design and performance characteristics of a turbulent mixing condensation nuclei counter, J. Aerosol Sci., 31, 933-944, 2000.

Noone, K. J. and Hansson, H. C.: Calibration of the Tsi 3760 Condensation Nucleus Counter for Nonstandard OperatingConditions, Aerosol Sci. Tech., 13, 478-485, 1990.

Okuyama, K., Kousaka, Y., and Motouchi, T.: Condensational Growth of Ultrafine Aerosol-Particles in a New Particle-Size Magnifier, Aerosol Sci. Tech., 3, 353-366, 1984.

Rose, C., Sellegri, K., Asmi, E., Hervo, M., Freney, E., Colomb, A., Junninen, H., Duplissy, J., Sipilä, M., Kontkanen, J., Lehtipalo, K., and Kulmala, M.: Major contribution of neutral clusters to new particle formation at the interface between the boundary layer and the free troposphere, Atmos. Chem. Phys., 15, 34133428, doi:10.5194/acp-15-3413-2015, 2015.

Saros, M. T., Weber, R. J., Marti, J. J., and McMurry, P. H.: Ultrafine aerosol measurement using a condensation nucleus counter with pulse height analysis, Aerosol Sci. Tech., 25, 200-213, 1996.

Seifert, M., Tiede, R., Schnaiter, M., Linke, C., Mohler, O., Schurath, U., and Strom, J.: Operation and performance of a differential mobility particle sizer and a TSI 3010 condensation particle counter at stratospheric temperatures and pressures, J. Aerosol Sci., 35, 981-993, 2004.

Sgro, L. A. and Fernández de la Mora, J.: A simple turbulent mixing $\mathrm{CNC}$ for charged particle detection down to $1.2 \mathrm{~nm}$, Aerosol Sci. Tech., 38, 1-11, 2004.

Sipilä, M., Lehtipalo, K., Attoui, M., Neitola, K., Petäjä, T., Aalto, P. P., O'Dowd, C. D., and Kulmala, M.: Laboratory Verification of PH-CPC's Ability to Monitor Atmospheric Sub-3 nm Clusters, Aerosol Sci. Tech., 43, 126-135, 2009.
Stolzenburg, M. R. and McMurry, P. H.: An Ultrafine Aerosol Condensation Nucleus Counter, Aerosol Sci. Tech., 14, 48-65, 1991.

Takegawa, N. and Sakurai, H.: Laboratory Evaluation of a TSI Condensation Particle Counter (Model 3771) Under Airborne Measurement Conditions, Aerosol Sci. Tech., 45, 272-283, 2011.

Ude, S. and Fernández de la Mora, J.: Molecular monodisperse mobility and mass standards from electrosprays of tetra-alkyl ammonium halides, J. Aerosol Sci., 36, 1224-1237, 2005.

Vanhanen, J., Mikkilä, J., Lehtipalo, K., Sipilä, M., Manninen, H. E., Siivola, E., Petäjä, T., and Kulmala, M.: Particle Size Magnifier for Nano-CN Detection, Aerosol Sci. Tech., 45, 533-542, 2011.

Wimmer, D., Lehtipalo, K., Franchin, A., Kangasluoma, J., Kreissl, F., Kürten, A., Kupc, A., Metzger, A., Mikkilä, J., Petäjä, T., Riccobono, F., Vanhanen, J., Kulmala, M., and Curtius, J.: Performance of diethylene glycol-based particle counters in the sub-3 nm size range, Atmos. Meas. Tech., 6, 1793-1804, doi:10.5194/amt-6-1793-2013, 2013.

Xiao, S., Wang, M. Y., Yao, L., Kulmala, M., Zhou, B., Yang, X., Chen, J. M., Wang, D. F., Fu, Q. Y., Worsnop, D. R., and Wang, L.: Strong atmospheric new particle formation in winter in urban Shanghai, China, Atmos. Chem. Phys., 15, 1769-1781, doi:10.5194/acp-15-1769-2015, 2015.

Yu, H., Gannet Hallar, A., You, Y., Sedlacek, A., Springston, S., Kanawade, V., Lee, Y. N., Wang, J., Kuang, C., McGraw, R. L., McCubbin, I., Mikkilä, J., and Lee, S. H.: Sub$3 \mathrm{~nm}$ particles observed at the coastal and continental sites in the United States, J. Geophys. Res.-Atmos., 119, 860-879, doi:10.1002/2013JD020841, 2014.

Zhang, Z. Q. and Liu, B. Y. H.: Dependence of the Performance of Tsi 3020 Condensation Nucleus Counter on Pressure, Flow-Rate, and Temperature, Aerosol Sci. Tech., 13, 493-504, 1990.

Zhang, Z. Q. and Liu, B. Y. H.: Performance of Tsi 3760 Condensation Nuclei Counter at Reduced Pressures and Flow-Rates, Aerosol Sci. Tech., 15, 228-238, 1991. 